\title{
Assessment of knowledge of medical post graduate students regarding promotional drug literature using WHO criteria
}

\author{
Shikha Jaiswal ${ }^{1}$, Tikam Singh Dhruw ${ }^{2, *}$, Rajesh Hishikar ${ }^{3}$, Raka Sheohare ${ }^{4}$, Ajay Halwai ${ }^{5}$ \\ 1,5 Assistant Professor, ${ }^{2}$ Demonstrator, ${ }^{3}$ Professor and HOD, ${ }^{4}$ Consultant Diabetologist, Dept. of Pharmacology, ${ }^{\mathbf{1 , 2 , 3 , 5}} \mathrm{Pt}$. Jawahar Lal Nehru \\ Memorial Medical College, Raipur, Chhattisgarh, ${ }^{4}$ Madhumeet Diabetes Hospital, Raipur, Chhattisgarh, India
}

*Corresponding Author: Tikam Singh Dhruw

Email: drtsdhruw@gmail.com

\begin{abstract}
Objective: Pharmaceutical promotional activities create potential for inappropriate prescribing practices without necessarily benefiting the patients but contributes to increased health care costs if prescriber is not aware of WHO criteria for ethical medical drug promotion 1988. So this study was conducted with objective to assess the knowledge of medical post graduate students about WHO criteria for promotional drug literature.

Materials and Methods: This observational study was conducted in the various departments of Pt. J. N. M. Medical College \& associated Dr. B.R. Ambedkar Memorial Hospital Raipur (C.G.). 100 medical post graduate students were given a promotional drug literature \& were asked to evaluate it according to WHO Criteria on prescribed proforma.

Results: 33\% Medical Post Graduate students were aware of WHO criteria. 14\% students evaluated importance of reference of scientific literature. $29 \%$ evaluated importance of name and address of manufacturer or distributor. $33 \%$ evaluated necessity of dosage form or regimen. $70 \%$ evaluated the importance of active ingredients. $76 \%$ students evaluated the importance of other ingredients or adjuvant known to cause problem. $80 \%$ students evaluated the importance of major drug interactions. $95 \%$ students evaluated the importance of the amount of active ingredients per dosage form. $96 \%$ students evaluated importance of drug related precautions, contraindications and warnings. 98\% evaluated the importance of side effects and major adverse drug reactions. 100\% students evaluated the importance of brand name and approved therapeutic uses.

Conclusion: The study showed that medical post graduate students have little knowledge about WHO Criteria of promotional drug literature. They require constant education regarding WHO guidelines as these literatures often influence prescribing behaviours of physicians.
\end{abstract}

Keywords: WHO criteria, Promotional, Drug, Literature, Students.

\section{Introduction}

World Health Organization (WHO) defines medicinal drug promotion as "all informational and persuasive activities done by manufacturer and distributors so as to induce the prescription, supply, purchase and use of drugs which are medicinal". ${ }^{1}$ Drug brochures, visual aids, audio visual and hand outs are the different modes of drug promotion. Medical representatives are the channels most commonly utilized in disseminating this informations. Direct to physician marketing is being practiced very much by both drug manufacturers as well as distributors by means of medical representatives. ${ }^{2}$ IFPMA is the international federation of pharmaceutical manufacturers and association and is responsible for setting ethical promotion standards for member countries. ${ }^{3}$ Self regulatory code of pharmaceutical marketing practices, national legislation, organization of pharmaceutical producers of India are responsible for setting standards for promotional activities. All the promotion making claims about drugs should be accurate informative, up to date and ethical. They should not contain misleading, false and biased statement. Inadequate, inaccurate and false information that their products are better to existing drugs can lead to irrational and misleading prescription. WHO has recommended to adhere strictly to ethical criteria for improvement of health care by promoting rational use of medicines. It creates great necessity to properly evaluate the promotional material of the drug. ${ }^{4}$

Clinical post graduation (MD, MS) is the time when medical postgraduates come in contact with pharmaceutical companies \& are prompted to write their products. Being a medical graduate he must have certain information before prescribing drugs. WHO Expert committee on the use of essential drugs have an illustration of the type of information that the advertisements \& reminders should contain. ${ }^{5}$ One of the well known promotional activities of pharmaceutical industries is to produce advertising brochures which at times are inaccurate and of poor educational value. ${ }^{6-9}$ Pharmaceutical promotional activities create potential for inappropriate prescribing practices without necessarily benefiting the patients but contributes to increased health care costs if prescriber is not aware of WHO criteria for ethical medical drug promotion $1988 .{ }^{10}$ Very few studies have been carried out in India to evaluate the knowledge of promotional drug literature, so this study was conducted with objective to assess the knowledge of medical post graduate students about WHO criteria for promotional drug literature.

\section{Materials and Methods}

This observational study was conducted in the various departments of Pt. J.N.M.Medical College \& associated Dr. B. R. Ambedkar Memorial Hospital Raipur (C.G.) 100 medical post graduate students were given a promotional drug literature \& were asked to evaluate it according to WHO Criteria on prescribed proforma under following headings. 
1. The names of the active ingredients using either international non-proprietary names (INN) or the approved generic name of the drug;

2. The brand name;

3. Content of active ingredient(s) per dosage form or regimen;

4. Name of other ingredients known to cause problems;

5. Approved therapeutic uses;

6. Dosage form or regimen;

7. Side-effects and major adverse drug reactions;

8. Precautions, contra-indications and warnings;

9. Major interactions;

10. Name and address of manufacturer or distributor;

11. Reference to scientific literature as appropriate.

Reminder advertisements lought to include at least the brand name, the international non-proprietary name or approved generic name, the name of each active ingredient, and the name and address of the manufacturer or distributor for the purpose of receiving further information. ${ }^{1}$

Data were collected and knowledge of every point of WHO CRITERIA was evaluated in percentage.

\section{Results}

100 Medical Post Graduate students were assessed for knowledge of promotional drug literature using WHO criteria and following results are obtained.

$14 \%$ Medical Post Graduate students evaluated importance of reference of scientific literature .29\% evaluated importance of name and address of manufacturer or distributor. 33\% Medical Post Graduate students were aware of WHO criteria. 33\% evaluated necessity of dosage form or regimen. $70 \%$ evaluated the importance of active ingredients.76\% students evaluated the importance of other ingredients or adjuvant known to cause problem. $80 \%$ students evaluated the importance of major drug interactions $.95 \%$ students evaluated the importance of the amount of active ingredients per dosage form. $96 \%$ students evaluated importance of drug related precautions, contraindications and warnings. $98 \%$ evaluated the importance of side effects and major adverse drug reactions. $100 \%$ students evaluated the importance of brand name and approved therapeutic uses.

There are so many irrationalities and unethical practices prevailing in the health care segment and the ultimate sufferer is the patient. Therefore, the health care professional should have knowledge of these promotional activities. There are numerous scopes for new laws and regulations for identifying and penalizing these unethical practices. These include mandated disclosure by pharmaceutical companies of the expenditure incurred on drug promotion and disqualification of the product and penalty on the company for unethical drug promotional literature. No laws or regulations can ever change the scenario. It is one's own responsibilities, attitude and conscience that have to be altered and everyone should work as if the ultimate motto is patient safety and benefit. By doing so, at each and every step of health care delivery; improvements can be achieved as a whole. ${ }^{5}$

\section{Discussion}

Most easily available, easily accessible and important source of drug information is printed promotional literature. Indian market is flooded with many new and old drugs with only some alterations. Genuine inventions are rare, most of them are with altered formulations. In this study only one type of promotional activity was analyzed i.e printed promotional literature, however there is need to assess the awareness and knowledge of the practitioners by intervention study and provide guidance about accurate and ethical information from Drug Promotional Literatures. Direct to prescriber method of marketing may influence prescribing behavior with no benefit to the patient and also lead to irrational prescribing practices. Drug manufacturers and practitioners should strictly follow the laws. They can make aware and strengthen the already existing guidelines which can have some promising results in health care. Indeed efforts of practitioners, pharmaceutical companies and regulatory body is needed which is the only way to accomplish rational prescribing. ${ }^{1}$

Mumbai, New Delhi, Chennai and Chandigarh are the centres for regional ethics committee which collect complaints against unethical drug promotion advertisements. Further these complaints are forwarded to drug controller authority so that necessary legal actions could be taken against guilty companies. ${ }^{2}$ Education on how to assess pharmaceutical promotion and how to understand its effect on their prescribing behaviour is lacking in our health care system. Medical representatives also lack sufficient medical and technical knowledge to present information on pharmaceutical products correctly and in a responsible manner. ${ }^{3}$

"Pharmaceutical product" means all pharmaceutical or biological products which are intended for use in the diagnosis, treatment or prevention of disease in humans, or to affect the structure or any function of the human body. ${ }^{11}$

Mistreatment, overtreatment, and under treatment are the consequences of inadequate and unethical drug promotion. Mistreatment has led to uncontrolled use of new drugs with almost similar efficacy but side effect profile when compared with old products, it is even more worse. In many instances where only behavioral therapies could have given satisfactory results, drugs are being prescribed. Overtreatment- In mild pain, viral infections where only limited drugs are required, many drugs are prescribed irrationally. Over diagnosis may also lead to overtreatment. Disadvantages of overtreatment are antibiotic resistance, unnecessary toxicity and diversion of resources from those who really need them. Under treatment- Pharmaceutical companies are mainly promoting blockbuster drugs which can bring high profits and populations with rare diseases are neglected as profit associated with drugs for rare diseases are very less as compared to blockbuster drugs.

World Health Organization has put forward guidance through World Health Assembly regarding ethical criteria for medicinal drug promotion. Regulators, governments, and academics utilizes this regulations for measuring the acceptability of promotional activities. The criteria have 
also been incorporated into curriculums for educating health professionals about drug marketing techniques. WHO guidance documents are of great importance in countries where there is poor local regulation. ${ }^{12}$

Long term effects of drug marketing on health usually remains unseen. Drug promotion leads to financial burden on the patients as expensive drugs instead of cheaper ones are usually prescribed more although they are equally safe and effective. Similar is the case with branded and generic drugs. ${ }^{12}$

Appropriate educational background, adequate training, medical and technical knowledge should be the prerequisite for the medical representatives to present information on products and carry out other promotional activities in an accurate and responsible manner. Medical representatives should be constantly educated by their pharmaceutical companies and should be properly instructed regarding appropriate ethical conduct laid down by World Health Organisation. Medical representatives and trainees must take feed back from the medical personnel such as doctors so that particular attention can be given to the adverse effect profile of the drugs promoted. Pharma drug companies should take the responsibilities of all the activities and promotion done by their medical representatives and if any kind of wrong information is conveyed, it should be rectified promptly. It is possible only when feedback is taken by medical representatives whenever any drug is promoted. This activity may play a great role in improving the health care of majority of the population. Various training programmes, symposia, workshops should be organised by the scientific or professional bodies to make aware health care professionals about ethics of drug promotional activities.

Approved medicinal drugs undergo post-marketing clinical trials which play an important role in ensuring rational use of drugs. The results of this trial should be made available to appropriate authority so that it can be disseminated as soon as possible. This studies should not be misused as a drug promotion. All the information regarding adverse effects should be reported as a priority to the appropriate national health authority as well as to the health authority internationally. Regular training will improve performance, capability, productivity and capacity. This type of continuing education will directly lead to the improvement in human resources in health sector. Evidence based medicine can be practiced with the help of various valuable information obtained by critical evaluation of promotional literature. Primary focus of Indian health policy should be medical education. The quality of medical education should be improved and in medical colleges curriculum should be updated. Each and every country must improve their health system by getting right number of service providers with right skills at the right place and this is also suggested by World Health Organization . ${ }^{1}$

In a study conducted by Hasina Sayyad educational training was given due importance in undergraduate medical students. Information about medicines is necessary to help prescribers. To practice rational drug therapy knowledge about medicine is essential so as to disseminate information accurately. Improvement in knowledge about promotional brochures and commenting and criticizing abilities of undergraduate students after the training programme was found to be statistically significant. In India, promotional activities may play an important infuential role because in India prescription writing is not limited only to qualified doctors but also unregistered doctors, quacks and even chemists do write prescriptions. In remote areas, prescribers do not have any other access to latest information and solely dependent upon promotional literatures. Weak industry guidelines for drug promotion, are not enough to deal with misleading advertisements. Appropriate government regulations, and a powerful complaint handling system should be established to deal with misleading promotions. ${ }^{13}$

In another study conducted by Alvero RGY on teaching critical appraisal of promotional brochures in a medical school in Philippines, it was found that intervention scores were significantly higher after teaching module on critical appraisal of medicinal drug promotion as compared to those who did not undergo teaching. It has been observed that teaching programmes or educational initiatives are lacking which are needed to teach drug promotion to medical students. So more attention is required and sincere efforts must be taken by medical school or colleges to conduct more and more such programs so as to increase awareness among medical students and emphasise it in the routine curriculum. ${ }^{14}$

\section{Conclusion}

The study showed that medical post graduate students have little knowledge about WHO Criteria of promotional drug literature. They require constant education regarding WHO guidelines as these literatures often influence prescribing behaviours of physicians.

\section{References}

1. Ethical criteria for medicinal drug promotion. World Health Organization, 1988.

2. Gopalakrishnan S, Murali R. 2002. India: Campaign to tackle unethical promotion. Essential Drug Monitor.

3. International Federation of Pharmaceutical Manufacturers and Associations (IFPMA).2012.

4. Khakhkhar T, Mehta M, Shah R, Sharma D. Evaluation of drug promotional literatures using WHO guidelines. Journal of Pharmaceutical Negative Results, 2013; 4(1).

5. WHO Technical report series no.722,1985,p.43

6. Mali SN, Dudhgaonkar S, Bachewar N P. Evaluation of rationality of promotional drug literature using World Health Organization guidelines. Indian J Pharmacol. 2010;42:26-72.

7. Loke TW, Koh FC, Ward JE. Pharmaceutical advertisement claims in Australian medical publications: Is evidence accessible, compelling and communicated comprehensively? Med J Aust. 2002;177(6):291-293.

8. Rohra DK, Gilani AH, Memon IK, Perven G, Khan MT, Zafar H, Kumar R. Critical evaluation of claims made by pharmaceutical companies in drug promotional material in Pakistan. J Pharm Pharmaceut Sci. 2006;9:50-9.

9. Villanueva P, Peiro S, Librero J, Pereiro I. Accuracy of pharmaceutical advertisements in medical journals. Lancet. 2003;361:27-32. 
10. Rohit Dixit, Prabhakar Patil, Chandrashekar, Rajesh C S, Sudha Madhuri, Abhay Mane. DRUG promotional activities as a source of medical information and its influence on prescribing. IJPBS. 2014;4(3):113-119.

11. Parli K, Reema R, Devang R and Supriya M: Evaluation of promotional drug literature provided by medical representative at a tertiary care hospital. Int J Pharm Sci Res. 2017;8(4):17441750.

12. Lisa Parker Jane Williams Lisa Bero.Ethical drug marketing criteria for the 21st century. BMJ. 2018;361:k1809.

13. Hasina Sayyad, Ghongane B.B, Shahid Saache, Smita Tiwari "Teaching critical appraisal of drug promotional brochures on ability of medical students to identify violations of existing WHO Guidelines" IOSR. J Dent Med Sci (IOSR-JDMS) e-
ISSN: 2279-0853, p-ISSN: 2279-0861. Volume 16, Issue 2 Ver. I (February. 2017), PP 43-48 www.iosrjournals.org

14. Alvero RGY and Panganiban DL, Teaching critical appraisal of medicinal drug promotions in a medical school. World Health Organization, 2008. Available at http://archives.who.int/icium/icium1997/posters/2a1_text.

How to cite this article: Jaiswal S, Dhruw $\mathrm{T} S$, Hishikar R, Sheohare R, Halwai A. Assessment of knowledge of medical post graduate students regarding promotional drug literature using WHO criteria. Indian J Pharm Pharmacol. 2018;5(4):198-201. 